\title{
Development and Validation of the Energy-Issue Attitude Questionnaire: Relations with Energy Knowledge, Affect, and Behavior
}

\author{
Mei-Shiu Chiu ${ }^{1 *}$, Jan DeWaters ${ }^{2}$ \\ ${ }^{1}$ National Chengchi University, Taiwan \\ ${ }^{2}$ Clarkson University, Potsdam, NY, USA \\ Email: chium@nccu.edu.tw; meishiuchiu@gmail.com
}

\begin{abstract}
This study aims to develop the Energy-Issue Attitude Questionnaire (EIAQ). The EIAQ focuses on student responses to energy issues in society and includes ten constructs, organized pairwise with tension: energy-saving vs. carbon-reducing knowledge, having vs. being lifestyles, questioning vs. conforming to authorities, technology vs. nature approaches, and future vs. present goals. The EIAQ was validated with a criterion questionnaire on energy literacy, including knowledge, affect and behavior. Research participants were 4,689 Taiwanese secondary students. The results show that the EIAQ has desirable construct validity and reliability. Significant differences occur between the two attitudes in each pair. Energy attitudes have medium correlations with energy affect and behavior but low correlations with energy knowledge. The results of structural equation modeling show that energy behavior is directly predicted by 'being' lifestyles and conformity to authorities, and indirectly predicted by energy-saving knowledge, mediated by energy affect.
\end{abstract}

Keywords: Energy attitudes; energy behavior; energy issues; energy knowledge; adolescence

\section{$1 \quad$ Introduction}

People tend to have diverse or vague attitudes toward energy issues and are insufficiently inclined to conduct energy-conservation behavior (Whitmarsh, 2009) even with sufficient energy knowledge (Liarakou, Gavrilakis, \& Flouri, 2009). These vague energy attitudes and behaviors appear to contradict the scientific evidence that humans are the main cause of global warming (Intergovernmental Panel on Climate Change [IPCC], 2010). The diversity in energy attitudes may result from the emerging knowledge of global warming, on-going scientific research on energy innovations, and demands for the reduction of economic development (Rogelj, McCollum, \& Riahi, 2013; Yu, Yang, \& Chou, 2002).

Energy attitudes tend to be culture-dependent, a reflection of interactions and tensions between personal cultural values, manifest lifestyle, societal hyper-structure, and household systems (Keirstead, 2006). Energy behavior is considered direct, effective, feasible, and economical actions to mitigate global warming (Weber, 1997). Demographics, e.g., gender, age, and socioeconomic status (SES), may need to be taken into account in energy attitude and behavior. The two major objectives of this study, therefore, are: (1) to identify and evaluate the diverse energy attitudes toward energy issues presented in a specific culture, Taiwan, and (2) to investigate the link between energy attitudes and behavior with demographics. The findings may help identify effective energy attitudes and actions for mitigating global warming.

\subsection{Defining Energy Attitudes in Terms of Energy Issues in Society}

Energy attitudes may be best defined as cognitive and affective responses to energy issues and as motivators to energy behavior (Mweemba \& Wu, 2010). The debate on energy issues tends to be culturally dependent and exists worldwide. For example, Americans prefer nuclear energy, and carbon capture and storage (Fleishman, De Bruin, \& Morgan, 2010). Germans prefer renewable energies (Scheer, Konrad, \& Scheel, 2013). Swedes have a negative attitude to nuclear power because of perceived risk (Viklund, 2004). The Japanese public and scientists have raised energy security debates, anxiety, and 
worries since the nuclear accident of Fukushima Daiichi nuclear power plant caused by the earthquake and tsunami on 11th March, 2011 (Akabayashi, 2011; Vivoda, 2012).

Similar to Japan, Taiwan faces potential geophysical threats, with frequent earthquakes, and two of the three operating and the planned fourth nuclear power plants are located near the Ryukyu subduction zone, which may cause $\mathrm{Mw}$ 7.5-8.7 tsunami earthquakes (Wu, Chen, Turcotte, \& Rundle, 2013). The negative perception of and distrust in nuclear power appear to extend from Japan to Taiwan, as revealed by the anti-nuclear demonstration in which some 80,000 people took to the streets on 9th March, 2013 (http://udn.com/NEWS/NATIONAL/NATS3/7747519.shtml).

Energy attitudes, in terms of tensions in implementing energy policy in diverse cultures, may be conceptually defined as individuals' social reflections of scientific knowledge and the human operation of technological creations in relation to energy in the physical world. Further, energy attitudes may be best operationally defined as personal judgments on the competing approaches, controversial opinions, and unavoidable dilemmas in the implementation of energy policy in a society.

Energy attitudes and their diverse components may be best understood through qualitative studies. For example, Aune (2007) interviewed and observed energy use in two homes in Norway and found that positive energy attitudes may not be translated into behavior because of the perception of home as a haven, project, and arena for activities. Chiu (2013) interviewed 94 Taiwanese and found tensions in implementing energy policy in Taiwan since 2008. Her study identified one major tension (future vs. present) and four sub-tensions: knowledge bases between energy conservation and carbon reduction, lifestyles between having and being, social systems between authority and conformity, and creation boundaries between technology and nature, resulting in ten total constructs.

The generalizability of the findings obtained through qualitative studies needs to be validated for a larger population by quantitative studies, a mixed methodology as has been successfully used by Whitmarsh (2009). In this study, the ten energy issues with tensions identified in Chiu's (2013) qualitative study for a small sample of participants from Taiwan were used to develop a questionnaire on energy attitudes for a large sample of participants also from Taiwan.

\subsection{Relation of Demographics to Energy Attitudes and Literacy}

Research on relations between demographics and energy (or environment-related) attitudes and behaviors shows mixed results. Females appear to have higher environmental concerns and behavior than males (Swofford \& Slattery, 2010). Females, on the other hand, appear to face more difficulties in integrating their diverse attitudes into harmonic action-oriented outcomes than males (Chiu, 2010). Higher educated people tend to have more pro-environment behavior than less educated people (Raymond \& Brown, 2011). Richer, younger, and lower educated people have higher perceptions of risk in energy technology use (e.g., nuclear power) (Hung \& Wang, 2011).

\subsection{Roles of Energy Attitudes in Energy Behavior}

Energy attitudes can be seen as the intrinsic motivation (including values, beliefs, and personal norms) toward energy behavior and are expected to take a major, effective, and persistent role in energy behavior or achievement (Pintrich, 2003; Stern, 2000). The discrepancy between energy attitude and energy conservation behavior, however, appears to be large (Viklund, 2004). For example, Lee, Lin, Guu, Chang, and Lai's (2013) hands-on energy education program increases student energy knowledge and later behavior but fails to increase energy attitudes.

Scholars have posited reasons for the weak role of energy attitudes in energy behavior and attempted to amend this weakness. External conditions, e.g., availability of necessary equipment, may serve as critical precedents for transforming positive energy attitudes into energy behavior (Guagnano, Stern, \& Dietz, 1995; Whitmarsh, 2009). The deficit in education or information transmission of scientific knowledge needs to be amended by deliberate, interactive, and timely communication and skill-focused teaching based on an understanding of the social context (Owens \& Driffill, 2008). Barriers need to be understood and then decreased by designing, piloting, and evaluating energy programs in communities (McKenzie-Mohr, 2000) and assessing motivation, capability, implementation, and results in energy industries (Chai \& Yeo, 2012). The use of society, culture, community, and context-based energy 
attitudes in this study are likely to increase the opportunities for finding a closer relationship between energy attitudes and behavior.

\section{$1.4 \quad$ Research Questions}

The above review of literature suggests that two aims should be addressed: (1) developing a questionnaire to investigate peoples' attitudes toward energy issues in society, and (2) identifying effective attitudes in relation to energy-conservation behavior. To address the first aim, a questionnaire called the Energy Attitude Questionnaire (EIAQ) was thus developed based on Chiu's (2013) qualitative research on tensions in implementing the energy policy in Taiwan for studying the same context. An existing criterion questionnaire, DeWaters and Powers' (2011) Energy Literacy Questionnaire (ELQ), and demographic data were used together with the EIAQ to address the second aim. This results in research questions as follows.

1. What are the internal reliability and construct validity of the EIAQ?

2. What are the differences and relations between the two constructs (energy attitudes) with tension in the EIAQ? (for content validity)

3. What are the relations between energy attitudes and energy literacy (knowledge, affect, and behavior)? (for criterion validity)

4. What are the relations of gender, grades, and SES with energy attitudes and energy literacy? (for discriminant validity)

5. What is the model that addresses the role of energy attitudes in energy behavior?

\section{$2 \quad$ Method}

\subsection{Sample}

The research participants were 4,689 students (2,384 girls) from 119 classes of 23 secondary schools in Taiwan. The participants included 1,964 students from 11 middle schools (Grades 7-9) and 2,725 students from 12 high schools (Grades 10-12). Each school had 3-9 classes participating in this study. The schools were sampled by balancing residential areas and populations, including students from cities, towns, and rural areas around Taiwan. The schools and students all agreed beforehand to participate in this study.

\section{$2.2 \quad$ Measures}

The Energy-Issue Attitude Questionnaire (EIAQ). The EIAQ was developed in this study based on Chiu's (2013) qualitative study conducted during 2010-2011. The 38-item EIAQ included ten constructs, in each pair: energy-saving vs. carbon-reducing knowledge, having vs. being lifestyles, questioning vs. conforming to authorities, technology vs. nature approaches, and future vs. present goals. The first to the eighth constructs included four items for each construct, and the last two constructs included three items for each construct. Six experts from the fields of physics, chemistry, biology, earth science, educational psychology (testing), Chinese, and English examined the items, one expert working in primary school, two in secondary school, two in university, and one in a public science education institution, thus establishing expert validity.

The participants rated the items on a five-point Likert-type scale ranging from 5 (Agree strongly) to 1 (Disagree strongly). The items were randomly placed in the first part of the survey. Table 1 shows the factor loadings and Cronbach's alphas of the items in relation to their respective constructs. 
Table 1. Factor loadings and Cronbach's alphas for the items of the ten constructs in the energy-issue attitude questionnaire (EIAQ)

\begin{tabular}{|c|c|c|}
\hline Subscales and Items & $\alpha$ & $\begin{array}{l}\text { Factor } \\
\text { Loadings } \\
\end{array}$ \\
\hline Energy-Saving Knowledge & .747 & \\
\hline Earth's resources are limited and will be used up one day. & & .475 \\
\hline $\begin{array}{l}\text { Human activities spend a lot of energy, which is the main reason why Earth's resources are } \\
\text { running out. }\end{array}$ & & .528 \\
\hline Humans conserving energy can prevent Earth's resources from being used up so fast. & & .559 \\
\hline Using less electricity can conserve energy. & & .497 \\
\hline Carbon-Reducing Knowledge & .740 & \\
\hline Earth's temperature keeps rising, which causes climatic anomaly. & & .482 \\
\hline $\begin{array}{l}\text { Greenhouse gas produced by humans (e.g., } \mathrm{CO}_{2} \text { ) is the main reason why Earth's temperature } \\
\text { keeps rising. }\end{array}$ & & .541 \\
\hline Reducing greenhouse gas produced by humans can slow down Earth's increase in temperature. & & .564 \\
\hline Using less electricity can reduce the release of greenhouse gas. & & .543 \\
\hline Having Lifestyle & .760 & \\
\hline Making lots of money is important. & & .707 \\
\hline If I were rich, I would choose to live in a mansion. & & .729 \\
\hline Having a car (especially expensive cars) is very important. & & .829 \\
\hline Being able to shop often is important. & & .617 \\
\hline Being Lifestyle & .626 & \\
\hline Being able to lead a simple life is bliss. & & .445 \\
\hline Living in a healthy, energy-conserving home is important. & & .544 \\
\hline Use personal cars only when it's necessary. & & .526 \\
\hline I only buy what I really need. & & .389 \\
\hline Questioning Authorities & .817 & \\
\hline Powerful countries need to use more resources. (Reversed) & & .731 \\
\hline The government needs to use more energy than the common public. (Reversed) & & .871 \\
\hline Major industries need to use more energy. (Reversed) & & .964 \\
\hline Rich and powerful people need to use more resources. (Reversed) & & .844 \\
\hline Conforming to Authorities & .666 & \\
\hline Powerful countries should lead everyone to reduce carbon emissions. & & .580 \\
\hline $\begin{array}{l}\text { If the government introduces good energy-conservation/carbon-reduction policies, I'd be pleased } \\
\text { to follow them. }\end{array}$ & & .580 \\
\hline $\begin{array}{l}\text { If powerful people (e.g., the president, school principals, business owners, and major industries) } \\
\text { take part in energy-conservation/carbon-reduction, I would follow their action. }\end{array}$ & & .572 \\
\hline $\begin{array}{l}\text { Religious people will follow energy-conservation/carbon-reduction campaigns led by religious } \\
\text { leaders. }\end{array}$ & & .360 \\
\hline Technology Approaches & .724 & \\
\hline Complete switch to renewable energy can promote energy-conservation/carbon-reduction. & & .429 \\
\hline $\begin{array}{l}\text { Inventing energy-conserving electronics and vehicles can promote energy-conservation/carbon- } \\
\text { reduction. }\end{array}$ & & .565 \\
\hline $\begin{array}{l}\text { Choosing eco-friendly, energy-conserving materials to build houses can promote energy- } \\
\text { conservation/carbon-reduction. }\end{array}$ & & .586 \\
\hline $\begin{array}{l}\text { Reinforcing eco-friendly and energy-conservation-related industries can promote energy- } \\
\text { conservation/carbon-reduction. }\end{array}$ & & .523 \\
\hline Nature Approaches & .709 & \\
\hline Planting trees and protecting forests can promote energy-conservation/carbon-reduction. & & .511 \\
\hline
\end{tabular}




\begin{tabular}{|c|c|c|}
\hline Back-to-nature farming can promote energy-conservation/carbon-reduction. & & .458 \\
\hline Buying natural, eco-friendly merchandises can promote energy-conservation/carbon-reduction. & & .591 \\
\hline Reinforcing local production of goods can promote energy-conservation/carbon-reduction. & & .511 \\
\hline Future Goals & .690 & \\
\hline Energy-conservation/carbon-reduction is to allow our future generations to have a better life. & & .530 \\
\hline $\begin{array}{l}\text { Energy-conservation/carbon-reduction is to prevent humans' liveable environment from early } \\
\text { obliteration. }\end{array}$ & & .562 \\
\hline Energy-conservation/carbon-reduction is to allow humans to thrive for a long time. & & .604 \\
\hline Present Goals & .567 & \\
\hline Energy-conservation/carbon-reduction has a direct relationship with my current life. & & .533 \\
\hline Energy-conservation/carbon-reduction is to prevent natural disasters. & & .459 \\
\hline Energy-conservation/carbon-reduction is to allow us to lead a better life at the pr & & .539 \\
\hline
\end{tabular}

The Energy Literacy Questionnaire (ELQ). The ELQ included three sections: energy knowledge, affect, and behavior (DeWaters \& Powers, 2011). Energy knowledge was measured based on a typical maximum-performance test format, choosing one correct answer from five choices. The energy affect and behavior were measured on a five-point Likert-type scale. The original items in English were translated into traditional Chinese, the official language used in Taiwan, by a Chinese-English bilingual research assistant, and back translated by another. The experts examined the items for adapting the items to the context of Taiwan, so some original items were changed, as described below.

The ELQ includes the middle- and high-school versions of energy knowledge. This study used only the high-school version because the additional items used in the original high-school version appeared to be suitable for both middle- and high- school students in Taiwan according to the national curriculum. The original high-school version of energy knowledge included 38 items. Twelve items (including answers) were changed slightly in order to adapt them to the context of Taiwan. For example, the country name 'the United States' in the item, 'Which country provided the single largest volume of oil imported to the United States in 2007?', was changed to 'Taiwan', and its answer was changed from 'Canada' to 'Saudi Arabia'. Five items were deleted because the experts found it hard to obtain single correct answers. For example, the experts provided different answers to the item, 'Which resource provides most of the energy used in Taiwan each year?'. This procedure resulted in 33 energy-knowledge items in the Taiwanese version of the ELQ.

The US versions of the ELQ for middle and high schools have the same items on energy affect and behavior. All of the 17 items in the energy affect remained unchanged in the Taiwanese version, except for the changes in the country name. A sample item is 'Saving energy is important' (scale: $5=$ strongly agree $-1=$ strongly disagree). The US version of the ELQ included ten items on energy behavior. Two items, regarding heater and air-conditioner usage habits were excluded in the Taiwanese version because the descriptions of the behavior did not fit the context of Taiwan. As such, eight items on energy behavior were included in the Taiwan version. All the eight items remained unchanged, except an item adapted to the Taiwanese context: 'I turn off electronics (such as televisions and computers) when they are not being used' (scale: $5=$ almost always or always $-1=$ hardly ever or never), because we assumed that not every student had computers. Table 2 shows a comparison between the US and Taiwanese versions of the ELQ in student responses. The average percentages of correct responses to the items on energy knowledge are both $42 \%$ for the US and Taiwan, those of positive responses to energy affect items are $74 \%$ (US) and $66 \%$ (Taiwan), and those of positive responses to energy behavior items are $65 \%$ (US) and 60\% (Taiwan). The results appear to suggest a need to increase Taiwanese students' energy affect and behavior given their lower positive responses to the two aspects compared to their US counterparts. 
Table 2. Percentages (\%) of correct and positive responses on the US and Taiwan versions of the energy literacy questionnaire

\begin{tabular}{l|l|l|l|l|l|l|l|l|l}
\hline & \multicolumn{3}{|l|}{ Knowledge } & \multicolumn{3}{l|}{ Affect } & \multicolumn{3}{l}{ Behavior } \\
\hline & MS & HS & average & MS & HS & average & MS & HS & average \\
\hline $\begin{array}{l}\text { US: DeWaters \& Powers } \\
(2011, \text { p. } 1702)\end{array}$ & 40 & 44 & 42 & 73 & 74 & 74 & 66 & 63 & 65 \\
\hline Taiwan: This study & 32 & 51 & 42 & 60 & 71 & 66 & 58 & 62 & 60 \\
\hline
\end{tabular}

Note. Correct responses are only for the measure of energy knowledge, obtained by coding $1=$ correct and $0=$ incorrect answers. Positive responses are for the measures of energy affect and behavior, referring to student responses of 5 (agree strongly or almost always) or 4 (agree moderately or quite frequently) on a five-point Likerttype scale. MS = middle school; HS = high school.

Demographics. The research participants were asked for their genders, grades (school years), parents' vocations, and quantities of nine cultural and five material household possessions. The items of cultural household possessions (e.g., a desk to study at, a link to the Internet, and classic literature) and material ones (e.g., cellular phones, televisions, and cars) were taken from the student questionnaire of the Programme for International Student Assessment of 2009, developed by the Organisation for Economic Cooperation and Development (2012, p. 288).

\subsection{Data Collection}

The survey was administered through a Moodle system set up on the website of the corresponding author's university in Taiwan from September to October, 2011. The participants individually linked to the websites, keyed in passwords, and filled in the survey under their teachers' supervision during a school period (normally in computer-science class) in their schools' computer classrooms. The use of online survey saved energy and time in data collection and processing. The dataset contained no missing data because the Moodle system allowed for a no missing responses setting.

\subsection{Data Analysis}

The measure of SES was derived from four variables: fathers' and mothers' vocations, and cultural and material household possessions. The four variables were separately transformed into standardized $\mathrm{z}$ scores. The four sets of standardized $\mathrm{z}$ scores were summed and then transformed into standardized $\mathrm{z}$ scores, which formed the single score of SES for each participant.

Research Question (RQ) 1 was answered by internal reliability analysis and confirmatory factor analysis (CFA). RQs 2-5 were answered by repeated-measure t test, correlation analysis (RQs 3-4), and structural equation modeling (SEM), respectively. CFA and SEM were conducted using the LISREL 8.80 software (Joreskog \& Sorbom, 2007).

\section{$3 \quad$ Results}

\subsection{Reliability and Construct Validity of the EIAQ}

The EIAQ has acceptable internal reliability and construct validity. The values of Cronbach's alpha for the ten constructs range from .817 to .567. The a priori structure of the EIAQ includes ten constructs, each of which has four or three items (Table 1). The EIAQ was developed based on Chiu's (2013) framework, which can be seen as its theoretical basis. As such, CFA can be directly used to test its a priori structure. The results of CFA show that the a priori structure of the EIAQ is supported $(\times 2(620)$ $=10291.638, \mathrm{p}<.05 ; \mathrm{CFI}=.969 ; \mathrm{NNFI}=.965 ; \mathrm{RMSEA}=.058)$. The values of factor loading from the ten constructs to their items are from .964 to .360 . 


\subsection{Differences and Relations between the Two Attitudes with Tensions in the EIAQ}

Significant differences are found between the two attitudes in each pair in the EIAQ. Table 3 shows that the students believe in energy-saving knowledge more than carbon-reducing knowledge, value a being lifestyle more than a having one, conform to authorities more than question authorities, prefer a technology approach to a nature approach, and aim at the future more than the present for energy issues. All the differences are not only significant but also with large effect sizes in lifestyle $(\eta 2=.441)$ and attitudes to authorities $(\eta 2=.281)$, a medium effect size in knowledge $(\eta 2=.135)$, and small effect sizes in approaches $(\eta 2=.032)$ and goals $(\eta 2=.026)$.

Table 3. Descriptive statistics, mean difference and repeated measures t-test results for the measures of energy attitudes, energy literacy, and demographics

\begin{tabular}{|c|c|c|c|c|}
\hline & \multirow[b]{2}{*}{ Mean } & \multirow[b]{2}{*}{ SD } & \multicolumn{2}{|c|}{ Mean- difference test } \\
\hline & & & $\mathrm{F}$ & $\eta 2$ \\
\hline \multicolumn{5}{|l|}{ Energy Attitudes } \\
\hline Energy-Saving Knowledge & 4.332 & .599 & 732.189 & .135 \\
\hline Carbon-Reducing Knowledge & 4.141 & .624 & & \\
\hline Having Lifestyle & 3.065 & .824 & 3703.845 & .441 \\
\hline Being Lifestyle & 4.017 & .613 & & \\
\hline Questioning Authorities & 3.251 & .943 & 1834.344 & .281 \\
\hline Conforming to Authorities & 3.991 & .632 & & \\
\hline Technology Approaches & 4.162 & .611 & 157.192 & .032 \\
\hline Nature Approaches & 4.079 & .628 & & \\
\hline Future Goals & 4.193 & .680 & 123.577 & .026 \\
\hline Present Goals & 4.092 & .674 & & \\
\hline \multicolumn{5}{|l|}{ Energy Literacy } \\
\hline Energy Knowledge $(1 \sim 0)$ & .430 & .178 & & \\
\hline Energy Affect & 3.852 & .504 & & \\
\hline Energy Behavior & 3.818 & .658 & & \\
\hline \multicolumn{5}{|l|}{ Demographics } \\
\hline Gender $(0=$ boy; $1=\operatorname{girl})$ & .508 & .500 & & \\
\hline Grades $(0=\mathrm{MS} ; 1=\mathrm{HS})$ & .581 & .493 & & \\
\hline Socioeconomic Status (z score) & .000 & 1.000 & & \\
\hline
\end{tabular}

Note. The score range for the energy attitudes, affect, and behavior is $5 \sim 1$, larger values indicating more in the meanings of the measures. The underlined values of $\mathrm{F}$ are significant at the .05 level. Small effect size: .01< $\eta 2$ (partial eta squared) <.06; medium effect size: $.06<\eta 2<.14$; large effect size: $\eta 2>.14$ (Cohen, 1988, p. 283). MS $=$ middle school; HS = high school.

The five pairs of energy attitudes show differential correlations between each other (Table 4). A high correlation is found between technology and nature approaches $(\mathrm{r}=.733)$; a moderate correlation is found between energy-saving and carbon-reducing knowledge $(\mathrm{r}=.688)$ and between future and present goals $(\mathrm{r}=.576)$; a very low correlation is found between having and being lifestyles $(\mathrm{r}=-.090)$ and between questioning and conforming to authorities $(\mathrm{r}=-.092)$. These results echo those obtained by the difference test in the previous section, with lower correlations suggesting larger differences between the two attitudes in each pair. 
Table 4. Correlations between the Measures of Energy Attitudes, Energy Literacy, and Demographics

\begin{tabular}{|c|c|c|c|c|c|c|c|c|c|c|c|c|c|c|c|}
\hline & 1 & 2 & 3 & 4 & 5 & 6 & 7 & 8 & 9 & 10 & 11 & 12 & 13 & 14 & 15 \\
\hline \multicolumn{16}{|l|}{ Energy-Saving Knowledge } \\
\hline Carbon-Reducing Knowledge & .688 & & & & & & & & & & & & & & \\
\hline Having Lifestyle & -.004 & .075 & & & & & & & & & & & & & \\
\hline$\underline{B e i n g ~ L i f e s t y l e ~}$ & .497 & .485 & -.090 & & & & & & & & & & & & \\
\hline Questioning Authorities & .008 & -.074 & .482 & -.042 & & & & & & & & & & & \\
\hline Conforming to Authorities & .571 & .565 & .022 & .564 & -.092 & & & & & & & & & & \\
\hline Technology Approaches & .668 & .649 & .040 & .587 & -.045 & .680 & & & & & & & & & \\
\hline$\underline{\text { Nature Approaches }}$ & .615 & .635 & .038 & .576 & -.074 & .634 & .733 & & & & & & & & \\
\hline Future Goals & .677 & .635 & .097 & .477 & -.066 & .531 & 613 & .583 & & & & & & & \\
\hline$\underline{\text { Present Goals }}$ & .536 & .502 & .077 & .439 & -.085 & .486 & .534 & .485 & .576 & & & & & & \\
\hline Energy Knowledge & .253 & .170 & .156 & .048 & .176 & .103 & 163 & .066 & .129 & .027 & & & & & \\
\hline Energy Affect & .591 & .487 & .289 & .444 & .231 & .486 & .551 & .472 & 468 & .356 & .452 & & & & \\
\hline$\underline{\text { Energy Behavior }}$ & .347 & .356 & .048 & .465 & -.054 & .429 & .412 & .404 & .314 & .279 & .065 & .355 & & & \\
\hline Gender $(0=$ boy; $1=\operatorname{girl})$ & .036 & -.011 & .163 & -.004 & 173 & .003 & -.021 & -.019 & -.006 & .012 & .139 & .167 & -.079 & & \\
\hline Grade $(0=\mathrm{MS} ; 1=\mathrm{HS})$ & .143 & .133 & .108 & -.002 & .027 & .074 & 107 & .040 & .098 & -.004 & .540 & .178 & .070 & .048 & \\
\hline Socioeconomic Status & .080 & .109 & .130 & -.008 & .037 & .080 & .086 & .047 & .056 & .022 & .139 & .098 & .093 & .001 & .171 \\
\hline
\end{tabular}

Note. The absolute values of correlation larger than .033 are significant at the .05 level. MS = middle school; HS = high school.

\subsection{Relations between Energy Attitudes and Energy Literacy}

The ten energy attitudes tend to show low correlations with energy knowledge $(\mathrm{r}=.253 \sim .027)$, moderate correlations with energy affect $(\mathrm{r}=.591 \sim-.289)$, and moderate to low correlations with energy behavior $(\mathrm{r}=.465 \sim-.048)$ in the ELQ (Table 4). Most of the correlations between energy attitudes and energy literacy are significantly positive. There are only four exceptions, i.e., the significantly negative correlations between the having lifestyle and energy knowledge $(\mathrm{r}=-.156)$, affect $(\mathrm{r}=-.289)$, and behavior $(\mathrm{r}=-.048)$ and between questioning authorities and energy behavior $(\mathrm{r}=-$ $.054)$, and a non-significant correlation between the present goal and energy knowledge $(\mathrm{r}=.027)$.

\subsection{Relation of Demographics to Energy Attitudes and Literacy}

Gender is only mildly related to energy attitudes in this study. Three significant correlations are found between gender and the attitudes regarding energy-saving knowledge $(r=.036$, girls $>$ boys, a positive value showing that girls have more energy-saving knowledge than boys), a having lifestyle $(\mathrm{r}=-.163$, girls $<$ boys $)$, and questioning authorities $(\mathrm{r}=.173$, girls $>$ boys $)$. Gender has significant but small correlations to energy knowledge $(\mathrm{r}=.139$, girls $>$ boys $)$, affect $(\mathrm{r}=.167$, girls $>$ boys $)$, and behavior $(\mathrm{r}$ $=-.079$, girls $<$ boys $)$.

Many significant correlations were found between educational level and energy attitudes. Compared with middle-school students, high-school students rated higher in energy-saving knowledge $(\mathrm{r}=.143)$, carbon-reducing knowledge $(\mathrm{r}=.133)$, having lifestyle $(\mathrm{r}=.108)$, conformity to authorities $(\mathrm{r}=.074)$, technology approaches $(\mathrm{r}=.107)$, nature approaches $(\mathrm{r}=.040)$, and future goals $(\mathrm{r}=.098)$. High-school students also have higher energy literacy in knowledge $(\mathrm{r}=.540)$, affect $(\mathrm{r}=.178)$, and behavior $(\mathrm{r}$ $=.070)$.

SES and energy attitudes showed many correlations. Compared with low SES students, high SES students rated higher in energy-saving knowledge $(\mathrm{r}=.080)$, carbon-reducing knowledge $(\mathrm{r}=.109)$, having lifestyle $(\mathrm{r}=.130)$, conformity to authorities $(\mathrm{r}=.080)$, technology approaches $(\mathrm{r}=.086)$, nature approaches $(\mathrm{r}=.047)$, and future approaches $(\mathrm{r}=.056)$, but showed less tendency to question authorities $(\mathrm{r}=-.037)$. In addition, high SES students have higher energy literacy in knowledge $(\mathrm{r}$ $=.139)$, affect $(\mathrm{r}=.098)$, and behavior $(\mathrm{r}=.093)$ than low SES students. 
It is important to note that all the correlations are small $(\mathrm{r}<.300)$, except that between grade and energy knowledge $(\mathrm{r}=.540)$. The large sample size in this study may explain why the small correlation coefficients are statistically significant.

\subsection{A Structural Model for the Role of Energy Attitudes in Energy Behavior (Partially Mediated by Energy Affect)}

A structural model for the role of energy attitudes in energy behavior was constructed based on three rationales. First, the two sets of constructs, 'energy-saving vs. carbon-reducing knowledge' in the EIAQ and 'energy knowledge' in the ELQ, share similar meanings. The shared meanings may result in multicollinearity (Aiken \& West, 1991) and thus create unreasonable path coefficients (larger than 1) when both are included in one single structural model. Second, the slightly higher correlations between energy attitudes and affect $(\mathrm{r}=.591 \sim-.289)$ relative to those between energy attitudes and behavior $(\mathrm{r}=.465$ $\sim$-.048) in the ELQ (Table 4) imply that energy affect may play a mediating role between energy attitudes and energy behavior (Hair, Black, Babin, \& Anderson., 2010). Third, the small but significant relations between demographics and energy attitudes and literacy suggest that demographics may not be included in the model but need to be controlled for. The model, therefore, excludes energy knowledge and includes energy affect as a mediator mediating the effect from energy attitudes to behavior (Figure 1).

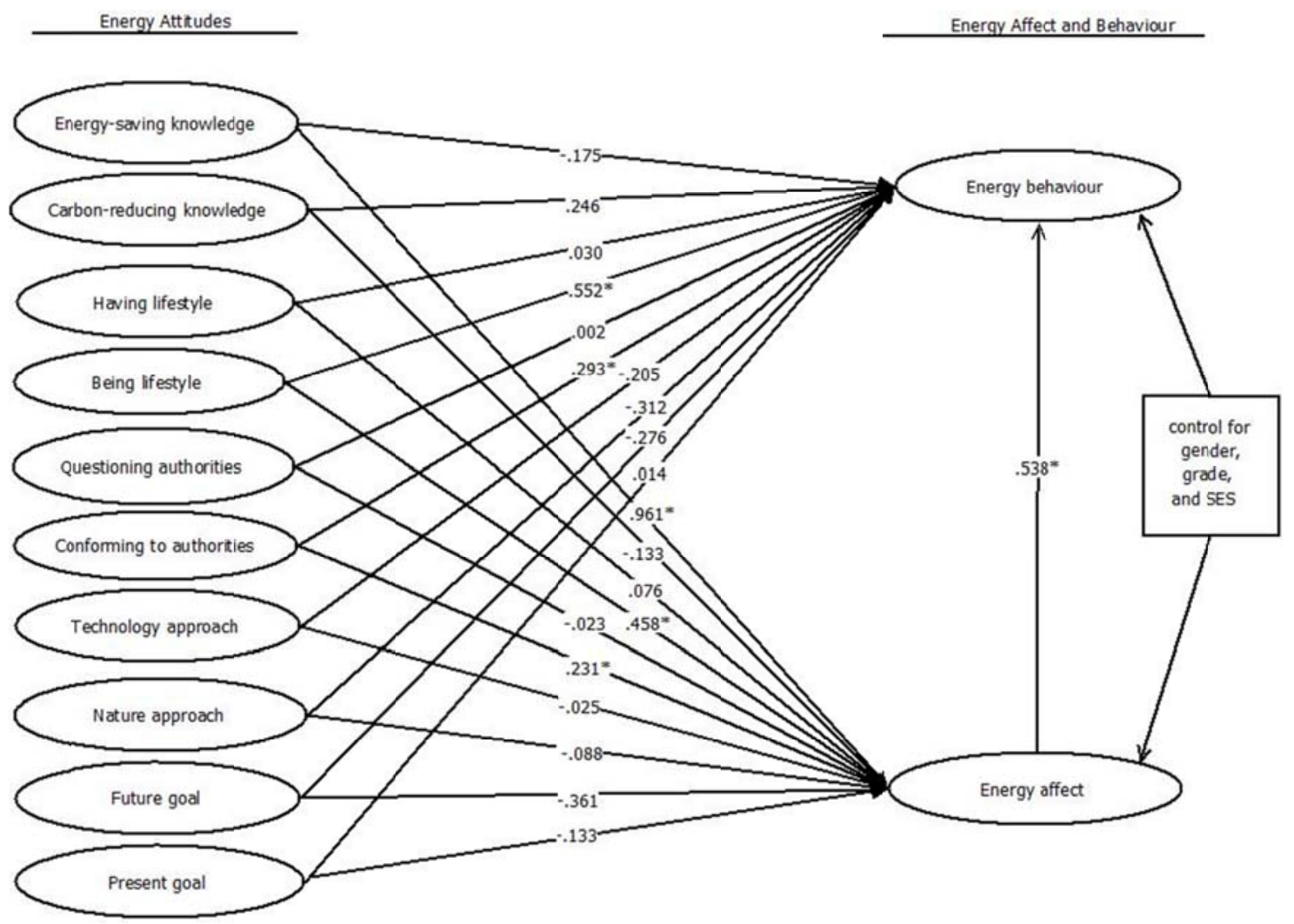

Figure 1. A structural model for the roles of energy attitudes in energy behavior (mediated by energy affect). SES $=$ socioeconomic status. ${ }^{*} \mathrm{p}<.05$

The results of SEM analysis show that the energy attitudes with a significant total effect on energy behavior are a being lifestyle and conforming to authorities, and the attitude with a significant indirect effect is energy-saving knowledge (Table 5). A being lifestyle has a significant direct effect (.552) and indirect effect (mediated by energy affect) (.247) on energy behavior, with a total effect of $.799(=.552$ $+.247)$. This means that a change in a being lifestyle by one standard deviation (SD), while holding the 
other independent variable constant, will change energy behavior (the dependent variable) by .799 units (SDs). Conforming to authorities also has a significant direct effect (.293) and indirect effect (.124) on energy behavior, with a total effect of .418 (slight difference with '.417 $=.293+.124$ ' because of rounding, cf. Table 5). This means that energy behavior will increase by .418 SDs for every one-unit increase in conforming to authorities. Energy-saving knowledge has a non-significantly negative direct effect (-.175) but a significantly positive indirect effect (.517) on energy behavior, with a positive total effect of .342, though not significant. The results suggest that we may effectively work on these three attitudes to promote energy-conservation behavior.

Table 5. Effects of energy attitudes on energy behavior

\begin{tabular}{l|l|l|l}
\hline & $\begin{array}{l}\text { Direct } \\
\text { Effect }\end{array}$ & $\begin{array}{l}\text { Indirect effect } \\
\text { (energy affect as mediator })\end{array}$ & Total effect \\
\hline Energy-Saving Knowledge & -.175 & $.517(=.961 \times .538)$ & .342 \\
\hline Carbon-Reducing Knowledge & .246 & $-.072(=-.133 \times .538)$ & .175 \\
\hline Having Lifestyle & .030 & $.041(=.076 \times .538)$ & .071 \\
\hline Being Lifestyle & .552 & $.247(=.458 \times .538)$ & .799 \\
\hline Questioning Authorities & .002 & $-.012(=-.023 \times .538)$ & -.010 \\
\hline Conforming to Authorities & .293 & $.124(=.231 \times .538)$ & .418 \\
\hline Technology Approaches & -.205 & $-.013(=-.025 \times .538)$ & -.218 \\
\hline Nature Approaches & -.312 & $-.048(=-.088 \times .538)$ & -.360 \\
\hline Future Goals & -.276 & $-.194(=-.361 \times .538)$ & -.470 \\
\hline Present Goals & .014 & $-.072(=-.133 \times .538)$ & -.057 \\
\hline
\end{tabular}

Note. The numbers and significance of the direct, indirect, and total effects are taken from the LISREL output (also cf. the path coefficients of Figure 1). Total effect $=$ direct effect + indirect effect. (Rounding decimal numbers results in some slight differences between the total effects and the sum of the direct and indirect effects and between the indirect effects and their calculation results.) The underlined values are significant at the .05 level.

\section{Discussion}

\subsection{Validation of the Energy Attitudes}

The EIAQ has been evidenced as an acceptable psychological measure for investigating student attitudes to the diverse issues with tensions in implementing energy policy worldwide (e.g., Viklund, 2004). The EIAQ has been developed based on the results of an exploratory qualitative study (Chiu, 2013), examined by experts, and further validated by internal reliability and construct, criterion, and theoretical validity analyses.

Diverse attitudes toward energy issues offer an authentic situation for scientific debate in energyeducation classrooms of multiple disciplines. Research indicates that desirable pedagogies for including energy issues in classrooms may focus on promoting student understanding of the role of science in society, awareness of the humanistic aspect of science, thinking of current socio-scientific problems for the relationships between causes, effects, and solutions, and development of scientific research skills and methods (Hofstein, Eilks, \& Bybee, 2011). To facilitate energy-issue classrooms, teachers may need to be aware of the different student attitudes regarding knowledge, lifestyles, social systems, approaches, and goals as indicated in this study, and incorporate these considerations into their pedagogies.

\subsection{Significant Energy Attitudes Related to Energy Behavior}

The attitudes of preferring a being lifestyle and conforming to authorities tend to play significant and stable roles in energy behavior. The results of SEM show that being lifestyle and conforming to authorities have significantly direct and indirect effects, while energy-saving knowledge only has an indirect role, mediated by energy affect, on energy behavior. 
The attitude of a being lifestyle tends to be consistent with the virtues of self-control, temperance, and moderation, cardinal values in most cultures and religions. Is virtue a necessity or an option for human beings? In order to meet the demands of morality when facing moral dilemmas regarding diverse issues (including energy issues), people have to reverse the 'greedy' and 'selfish' elements of human nature, e.g., 'not in my backyard' (West, Bailey, \& Winter, 2010, p. 5739) and 'not at my age' (Chiu, 2013, p. 422). If we see 'being lifestyle' as an 'attitude' then we have to acknowledge that human beings have diverse attitudes and may not make a being lifestyle their priority. A being lifestyle as part of moral identity is most easily transmitted and cultivated via family, early-years upbringing, and primary education, but gradually becomes an 'option' for teenagers afterwards. The present energy crisis may not allow us to take such a slow approach.

The significant and stable effect of conforming to authorities is consistent with Schelly, Cross, Franzen, Hall, and Reeve's (2012) finding that role modeling serves as an effective measure to implement school-based sustainability or energy education. The result, however, reveals a paradoxical phenomenon and dilemma in resolving energy issues. As a positive aspect, conforming to authorities is a sign of 'trust' in and willingness to follow 'big' others if things are going right (Ricc, Bellaby, \& Flynn, 2010, p. 2637). Convincing information and strict laws are necessary for 'changing' human behavior to 'morally' engaging in energy-conservation behavior. As a negative aspect, conforming to authorities implies that the reasoning and knowledgeable human being is an ideology or illusion. Citizens would have little chance to change, without proactive, comprehensive, and explicit direction from the government, as an authority figure, neglecting the momentum necessary to change the moral inertia of lifestyle (being vs. having) attitudes.

The present finding that energy-saving knowledge has an indirect role on behavior, mediated by affect, echoes the findings of Jho, Yoon, and Kim (2014). Their study shows that an energy teaching program emphasizing socio-scientific issues may increase student knowledge but fail to change student attitudes. The present finding further suggests that affect may play a mediating role in transforming knowledge into behavior. Future teaching programs may involve pedagogies for addressing this issue.

\subsection{Few Demographic Correlations to Energy Attitudes and Literacy}

Both energy attitudes and literacy have a few statistically significant correlations with gender, grades, and SES, but the correlations are generally small. The only substantial correlation occurs between grade and energy knowledge $(\mathrm{r}=.540>.300)$. The positive and moderate correlation reveals that high-school students substantially perform better in the traditional achievement test on energy knowledge than middle-school students.

More secondary education with development in age appears to relate to an increase in energy knowledge but fails to significantly relate to an increase in energy attitudes, affect, and behavior. The results suggest that it is difficult to directly transform energy knowledge into energy behavior, a result consistent with the information deficit hypothesis (Owens \& Driffill, 2008). A likely solution may be the infusion of energy affect into knowledge-based education because of the significant indirect effect of student energy-saving knowledge on energy behavior via energy affect (.517 in Table 5). Energy education has traditionally focused on knowledge and recent research has shown positive outcomes with the inclusion of hands-on activities (Zografakis, Menegaki, \& Tsagarakis, 2008). Teachers or policy makers may infuse energy affect, e.g., hope (Ojala, 2012), into the teaching of energy knowledge and action in order to promote better energy behavior.

\subsection{Conclusion, Limitations and Other Suggestions}

The EIAQ is developed based on the results of an exploratory qualitative study and has proved to be a psychological measure with acceptable reliability and validity. A structural model further validates the role of energy attitudes (esp. being lifestyle and conforming to authorities) on energy behaviors, mediated by energy affect. In conclusion, three major findings of this study are:

1. The Energy-Issue Attitude Questionnaire has desirable validity and reliability.

2. Energy behavior is predicted by a being lifestyle and conformity to authorities.

3. Energy-saving knowledge predicts energy behavior, mediated by affect. 
The findings, however, may be context-specific and need to be explained by the sampled subjects. Confucian culture and hierarchical collectivism in Taiwan are likely reasons for the significant roles of a being lifestyle and confirming to authorities in energy behavior. Further studies can include crosscultural or other context participants.

The present findings may provide suggestions for effective energy policy and education. A being lifestyle is part of morality and may be best cultivated in early stages of human development. Family and early years and primary education need to emphasize the value of a being lifestyle. For people after secondary education, conforming to authorities may be transformed into practice by the implementation of energy-behavior laws and the broadcasting of role models' energy behavior.

Energy education interventions can focus on increasing student emphasis on a being lifestyle, a nature approach, and energy affect, and decreasing student emphasis on a having lifestyle. The negative predicting capacity of the tendency to question authorities suggests that teachers may need to transform students' critical thinking of the emerging energy knowledge to energy-conservation behaviors, perhaps through the mediators of the positive predictors identified in this study.

Acknowledgments. This work was supported by the Ministry of Science and Technology, Taiwan (NSC100-3113-S-004-001; NSC102-3113-S-004-001; MOST 104-2410-H-004-143-MY2).

\section{References}

1. Aiken, L. S., \& West, S. G. (1991). Multiple regression: Testing and interpreting interactions. Newbury Park, CA: Sage.

2. Akabayashi, A. (2011). Fukushima research needs world's support. Nature, 471, 547.

3. Aune, M. (2007). Energy comes home. Energy Policy, 35, 5457-5465.

4. Chai, K. H., \& Yeo, C. (2012). Overcoming energy efficiency barriers through systems approach-a conceptual framework. Energy Policy, 46, 460-472.

5. Chiu, M.-S. (2010). Effects of science interest and environmental responsibility on science aspiration and achievement: Gender differences and cultural supports. Educational Research and Evaluation, 16, 345-370.

6. Chiu, M.-S. (2012). Gaps between valuing and purchasing green-technology products: Product and gender differences. International Journal of Technology and Human Interaction, 8(3), 54-68.

7. Chiu, M.-S. (2013). Tensions in implementing the "energy-conservation/carbon-reduction" policy in Taiwanese culture. Energy Policy, 55, 415-425.

8. DeWaters, J. E., \& Powers, S. E. (2011). Energy literacy of secondary students in New York State (USA): A measure of knowledge, affect, and behavior. Energy Policy, 39, 1699-1710.

9. Fleishman, L. A., De Bruin, W. B., \& Morgan, M. G. (2010). Informed public preferences for electricity portfolios with CCS and other low-carbon technologies. Risk Analysis, 30, 1399-1410.

10.Guagnano, G. A., Stern, P. C., \& Dietz, T. (1995). Influences on attitude-behavior relationships: A natural experiment with curbside recycling. Environment and Behavior, 27, 699-718.

11.Hair, J. F., Jr., Black, W. C., Babin, B. J., \& Anderson, R. E. (2010). Multivariate data analysis: A global perspective (7th ed.). Upper Saddle River, NJ: Pearson Education.

12.Hofstein, A., Eilks, I., \& Bybee, R. (2011). Societal issues and their importance for contemporary science education-A pedagogical justification and the state-of-the-art in Israel, Germany, and the USA. International Journal of Science and Mathematics Education, 9, 1459-1483.

13.Hung, H. C., \& Wang, T. W. (2011). Determinants and mapping of collective perceptions of technological risk: The case of the second nuclear power plant in Taiwan. Risk Analysis, 31, 668-683.

14.Intergovernmental Panel on Climate Change (2010). Meeting report of the Intergovernmental Panel on Climate Change Expert Meeting on detection and attribution related to anthropogenic climate change [Stocker, T. F., C.

B. Field, D. Qin, V. Barros, G.-K. Plattner, M. Tignor, P. M. Midgley, and K.L. Ebi (Eds.)]. IPCC Working Group I Technical Support Unit, University of Bern, Bern, Switzerland, pp. 55.

15.Jho, H., Yoon, H. G., \& Kim, M. (2014). The relationship of science knowledge, attitude and decision making on socio-scientific issues: The case study of students' debates on a nuclear power plant in Korea. Science \& Education, 23, 1131-1151. 
16.Joreskog, K. G. \& Sorbom, D. (2007). LISREL 8.80 [computer software]. Lincolnwood: Scientific Software International.

17.Keirstead, J. (2006). Evaluating the applicability of integrated domestic energy consumption frameworks in the UK. Energy Policy, 34, 3065-3077.

18.Lee, L. S., Lin, K. Y., Guu, Y. H., Chang, L. T., \& Lai, C. C. (2013). The effect of hands-on 'energy-saving house' learning activities on elementary school students' knowledge, attitudes, and behavior regarding energy saving and carbon-emissions reduction. Environmental Education Research, 19, 620-638.

19.Liarakou, G., Gavrilakis, C., \& Flouri, E. (2009). Secondary school teachers' knowledge and attitudes towards renewable energy sources. Journal of Science Education and Technology, 18, 120-129.

20.McKenzie-Mohr, D. (2000). Promoting sustainable behavior: An introduction to community-based social marketing. Journal of Social Issues, 56, 543-554.

21.Mweemba, L., \& Wu, H. (2010). Greening our future and environmental values: An investigation of perception, attitudes and awareness of environmental issues in Zambia. Environmental Values, 19, 485-516.

22. Ojala, M. (2012). Hope and climate change: The importance of hope for environmental engagement among young people. Environmental Education Research, 18(5), 625-642.

23. Organisation for Economic Cooperation and Development (2012). PISA 2009 technical report. OECD.

24.Owens, S., \& Driffill, L. (2008). How to change attitudes and behaviors in the context of energy. Energy Policy, $36,4412-4418$.

25.Pintrich, P. R. (2003). A motivational science perspective on the role of student motivation in learning and teaching contexts. Journal of Educational Psychology, 95, 667-686.

26.Raymond, C. M., \& Brown, G. (2011). Assessing conservation opportunity on private land: Socio-economic, behavioral, and spatial dimensions. Journal of Environmental Management, 92, 2513-2523.

27.Ricci, M., Bellaby, P., \& Flynn, R. (2010). Engaging the public on paths to sustainable energy: Who has to trust whom? Energy Policy, 38, 2633-2640.

28.Rogelj, J., McCollum, D. L., \& Riahi, K. (2013). The UN's 'Sustainable Energy for All' initiative is compatible with a warming limit of $2^{\circ} \mathrm{C}$. Nature Climate Change.

29.Scheer, D., Konrad, W., \& Scheel, O. (2013). Public evaluation of electricity technologies and future low-carbon portfolios in Germany and the USA. Energy, Sustainability and Society, 3(1), 1-13.

30.Schelly, C., Cross, J. E., Franzen, W., Hall, P., \& Reeve, S. (2012). How to go green: Creating a conservation culture in a public high school through education, modeling, and communication. Journal of Environmental Education, 43, 143-161.

31.Stern, P. C. (2000). Toward a coherent theory of environmentally significant behavior. Journal of Social Issues, $56,407-424$.

32.Swofford, J., \& Slattery, M. (2010). Public attitudes of wind energy in Texas: Local communities in close proximity to wind farms and their effect on decision-making. Energy Policy, 38, 2508-2519.

33.Viklund, M. (2004). Energy policy options-from the perspective of public attitudes and risk perceptions. Energy Policy, 32, 1159-1171.

34.Vivoda, V. (2012). Japan's energy security predicament post-Fukushima. Energy Policy, 46, 135-143.

35.Weber, L. (1997). Some reflections on barriers to the efficient use of energy. Energy Policy, 25, 833-835.

37.West, J., Bailey, I., \& Winter, M. (2010). Renewable energy policy and public perceptions of renewable energy: A cultural theory approach. Energy Policy, 38, 5739-5748.

36. Whitmarsh, L. (2009). Behavioral responses to climate change: Asymmetry of intentions and impacts. Journal of Environmental Psychology, 29, 13-23.

37.Wu, Y. H., Chen, C. C., Turcotte, D. L., \& Rundle, J. B. (2013). Quantifying the seismicity on Taiwan. Geophysical Journal International, 194, 465-469.

38.Yu, P.-S., Yang, T.-C., \& Chou, C.-C., (2002). Effects of climate change on evapotranspiration from paddy fields in southern Taiwan. Climatic Change, 54, 165-179.

39.Zografakis, N., Menegaki, A. N., \& Tsagarakis, K. P. (2008). Effective education for energy efficiency. Energy Policy, 36, 3226-3232. 